\title{
A Nova Prova Nacional de Seriação
}

\section{The New Medical Licensing Examination in Portugal}

João Carlos RIBEIRO $\triangle^{1,2}$, Tiago VILLANUEVA ${ }^{3,4}$

Acta Med Port 2018 Jun;31(6):293-294 - https://doi.org/10.20344/amp.10857

Palavras-chave: Avaliação Educacional; Competência Clínica; Licenciatura em Medicina

Keywords: Clinical Competence; Educational Measurement; Licensure, Medical

Portugal pode muitas vezes orgulhar-se de ter uma formação médica robusta, havendo quem considere que seja comparável aos países vistos como de topo nesta matéria. Mas para nos mantermos com a qualidade que pretendemos, temos de evoluir. O despacho $n .^{\circ} 4412 / 2018$ vem criar um novo modelo da Prova Nacional de Acesso à Formação Médica Especializada (PNA).

O antigo 'Harrison'1 foi foco de enorme controvérsia, amplamente discutido e contestado desde a sua implementação na década de 70. No entanto, sabemos que seriava bem, baseava-se num livro com uma qualidade reconhecida e com todo o historial, era previsível para os candidatos.

Um exame tem sempre duas faces, a de avaliação e a de formação. No caso da Prova Nacional de Acesso, ${ }^{2}$ à necessária seriação vem colar-se o ensino/formação médica. Numa altura em que a qualidade das vagas disponíveis para internato é cada vez mais frequentemente colocada em causa, a seriação assume um papel determinante na vida de um médico. O poder discriminativo da prova tem de ser cada vez maior. $\mathrm{O}$ facto de o número de itens aumentar será uma vantagem. Mas o 'Harrison' poderia ter 150 questões. Então, onde estão as vantagens em mudar? $\mathrm{Na}$ educação/formação médica.

O tempo e recursos que cada candidato despende no estudo do exame são desmedidos. E falamos de candidatos no período de vida em que estão no máximo das suas capacidades formativas. Não se conseguindo contornar a existência de uma prova pela necessidade de existir uma seriação, estes recursos devem ser melhor orientados. Uma das maiores críticas apontadas ao 'Harrison' reside no facto de seriar os candidatos pela capacidade de memorizar, muitas vezes, conhecimentos pouco ou nada úteis. Não vemos como o estudo do 'Harrison', num exame como o atual, valorize o raciocínio e prática clínica. A medicina não se resume certamente a cinco capítulos do 'Harrison'. Assim, se queremos colocar os nossos médicos a estudar, então que seja para benefício de todos, incluindo as várias dimensões da medicina, de acordo com aquilo que encontramos epidemiologicamente na população portuguesa. Os conteúdos e respectivas questões visam avaliar os conhe- cimentos e a capacidade de raciocínio clínico, situando estes critérios ao nível do corpo de conhecimentos que um médico sem formação médica especializada deve deter. Além do objectivo direto que a PNA tem de ter ao permitir seriar os candidatos, podemos ter várias outras vantagens acessórias. Ao valorizar o raciocínio clínico, e salientando a aplicação e integração dos conhecimentos adquiridos ao longo do percurso académico, estamos em crer que os próprios estudantes terão um cuidado extra em observar doentes durante as valências clínicas na faculdade.

Por outro lado, por a prova se realizar no final do curso, associado a um exame atual com matérias muito específicas e restritivas da medicina, é natural que os estudantes se foquem mais no estudo do que no contacto com os doentes. Com uma PNA baseada em vinhetas clínicas e no raciocínio clínico, todo o contacto supervisionado com os doentes será uma potencial mais-valia para a nova prova. Acreditamos que assim teremos mais estudantes com maior interesse na prática da medicina.

A prova atual valoriza excessivamente o espírito de sacrifício dos nossos médicos. O ensino clínico administrado nas faculdades é, no atual contexto, muito pouco relevante para um melhor lugar na seriação e consequente escolha de uma vida. Com a nova PNA, o tipo e qualidade de ensino nas faculdades será essencial para o candidato obter uma melhor classificação. Cada escola médica orgulha-se da sua perspetiva individual de ensino da medicina, existindo alguma preocupação quanto ao facto de as escolas médicas poderem orientar exclusivamente os seus curricula em direção a melhores resultados na prova, descurando as outras competências essenciais à formação de um bom médico. No entanto, pelo que se observou noutros países, isso não deverá ocorrer. ${ }^{3}$ Adicionalmente, o mesmo se poderia passar com os candidatos formados em universidades estrangeiras, com programas educativos dispares. Para estes, a PNA deve servir para o estudo de conteúdos mais adaptados à realidade epidemiológica nacional. E o facto de na PNA se valorizar a integração da prática da Medicina Geral e Familiar nos vários conteúdos, levará seguramente a um acréscimo da perceção que a medicina

1. Editor Associado. Acta Médica Portuguesa. Lisboa. Portugal.

2. Gabinete para a Prova Nacional de Acesso à Formação Especializada. Portugal.

3. Editor-chefe. Acta Médica Portuguesa. Lisboa. Portugal.

4. Editor Associado. BMJ e BMJ Open. Londres. Reino Unido.

$\bowtie$ Autor correspondente: João Carlos Ribeiro. jcarlosribeiro@uc.pt

Recebido: 28 de maio de 2018 - Aceite: 28 de maio de 2018 | Copyright $\odot$ Ordem dos Médicos 2018 
comunitária e de ambulatório deverão ter no futuro em Portugal.

Por outro lado, alguns poderão achar que a PNA servirá de benchmarking futuro em termos de faculdades, e isso talvez venha a acontecer. Contudo, devemos reter que um bom médico não tem apenas esta vertente, e que muitas competências não são avaliadas por uma prova com estas características. Acreditamos que o ensino médico tenderá a ser menos expositivo e mais diretamente clínico, com vantagens para todos. A PNA servirá certamente para consolidar os conteúdos mais prevalentes para um jovem médico poder exercer autonomamente.

A Acta Médica Portuguesa (AMP) tem por missão "ajudar os médicos a tomar as melhores decisões", daí termos mantido um interesse particular na publicação de trabalhos e editoriais em educação médica. O despacho que publica o novo modelo de prova (Despacho n 4412/2018, de 4 de Maio de 2018) evidencia um grande cuidado por parte do legislador com o uso das palavras. Se relativamente às dimensões de conteúdos este teve o cuidado de salientar que eram indicativas e não vinculativas, relativamente à bibliografia, destaca que são livros 'potenciais'. Isso significa que a utilidade da bibliografia, e mesmo a sua relevância para efeitos de reclamação, se esbate. As respostas às questões não terão de estar escritas num tratado específico, mas antes serem consensuais de acordo com a prática clínica. E aqui aumenta o potencial papel e responsabilidade da missão da AMP para com os médicos em Portugal.

A comissão encarregada de elaborar a prova será profissionalizada, com formação e apoio externos sustentados, com provas dadas e amplamente reconhecidas, o que nos dá uma grande garantia de qualidade, consistência e progressiva melhoria da PNA.

\section{REFERÊNCIAS}

1. Kasper DL, Fauci AS, Hauser SL, Longo DL, Jameson JL, Loscalzo J. Harrison's principles of internal medicine. 19 $9^{\text {th }}$ ed. New York: McGraw Hill Education; 2015.

2. Ministério da Saúde - Gabinete do Secretário de Estado Adjunto e da Saúde. Diário da República n. ${ }^{\circ}$ 86/2018, Série II de 2018-05-04, Despacho n 4412/2018.

3. Hateley P. A new national exam for medical students. Student BMJ. 2015;23:h4208.

4. Kies S. Materials employed by medical students preparing for subject examinations: supporting collection development. J Med Libr Assoc. 2008;96:158-61.
Apesar de tudo, é altamente desejável que os candidatos tenham acesso a materiais de preparação para a nova PNA. Em países como os Estados Unidos, Canadá, Reino Unido, entre outros, existe uma enorme quantidade e diversidade de materiais de preparação para exames equivalentes, que compreendem livros de revisão, bancos de perguntas e cursos, entre outros. ${ }^{4}$ Em outros países existe até alguma evidência de que a utilização de alguns destes materiais está associada a melhores resultados neste tipo de prova. ${ }^{5-7}$ É portanto muito provável que hajam e surjam rapidamente entidades interessadas em desenvolver materiais comerciais e não-comerciais de preparação para a nova PNA, tal como já existem para o exame 'Harrison'.

A AMP considera que poderá também contribuir de alguma forma para a formação dos candidatos relativamente a este modelo de prova, havendo várias possibilidades em aberto que incluem workshops sobre o tema e a publicação regular de questões do tipo vinheta clínica, de escolha múltipla com uma resposta mais correta entre cinco possíveis.

Por introduzir todo um novo paradigma de avaliação em Portugal, entendemos que a nova PNA esteja a gerar muita apreensão a nível dos atuais e futuros candidatos. É urgente por isso não só esclarecer todas as dúvidas em relação à sua importância, implementação e realização, como também assegurar que os candidatos tenham acesso a ferramentas adequadas de preparação para a prova.

\section{CONFLITOS DE INTERESSE}

João Carlos Ribeiro é membro do Gabinete para a Prova Nacional de Acesso à Formação Especializada. Tiago Villanueva é editor associado das revistas BMJ e BMJ Open. O BMJ Publishing Group produz materiais de preparação para provas de avaliação médica.
5. Bonasso P, Lucke-Wold B $3^{\text {rd }}$, Reed Z, Bozek J, Cottrell S. Investigating the Impact of Preparation Strategies on USMLE Step 1 Performance. MedEdPublish. 2015;4:1.

6. Alcamo AM, Davids AR, Way DP, Lynn DJ, Vandre DD. The impact of a peer-designed and -led USMLE Step 1 review course: improvement in preparation and scores. Acad Med. 2010;85:S45-8.

7. Levine RB, Levy AP, Lubin R, Halevi S, Rios R, Cayea D. Evaluation of a course to prepare international students for the United States Medical Licensing Examination step 2 clinical skills exam. J Educ Eval Health Prof. 2017;14.25. 